\title{
Article
}

\section{The Axenfeld-Rieger Syndrome Gene FOXC1 Contributes to Left-Right Patterning}

\author{
Paul W. Chrystal $1,2,3$, Curtis R. French ${ }^{1,2,4}$, Francesca Jean ${ }^{3}$, Serhiy Havrylov ${ }^{1,2}$, Suey van Baarle ${ }^{1,2}$, \\ Ann-Marie Peturson ${ }^{3}$, Pengfei Xu ${ }^{5}$, J. Gage Crump ${ }^{5}$, David B. Pilgrim ${ }^{3,6}$, Ordan J. Lehmann $1,2,6, *(1)$ \\ and Andrew J. Waskiewicz ${ }^{3,6, *(1)}$
}

1 Department of Medical Genetics, University of Alberta, Edmonton, AB T6G 2H7, Canada; pchrysta@ualberta.ca (P.W.C.); curtis.french@med.mun.ca (C.R.F.); havrylov@ualberta.ca (S.H.); vanbaar1@ualberta.ca (S.v.B.)

2 Department of Ophthalmology, University of Alberta, Edmonton, AB T6G 2H7, Canada

3 Department of Biological Sciences, University of Alberta, Edmonton, AB T6G 2E9, Canada; fjean@ualberta.ca (F.J.); apeturso@ualberta.ca (A.-M.P.); dave.pilgrim@ualberta.ca (D.B.P.)

4 Faculty of Medicine, Memorial University of Newfoundland, St John's, NL A1B 3V6, Canada

5 Department of Stem Cell Biology and Regenerative Medicine, Keck School of Medicine, University of Southern California, Los Angeles, CA 90033, USA; Pengfei.Xu@med.usc.edu (P.X.); gcrump@med.usc.edu (J.G.C.)

6 Women \& Children's Health Research Institute, University of Alberta, Edmonton, AB T6G 1C9, Canada

* Correspondence: olehmann@ualberta.ca (O.J.L.); aw@ualberta.ca (A.J.W.); Tel.: +1-(780)-492-8550 (O.J.L.); +1-(780)-492-4403 (A.J.W.)

check for

updates

Citation: Chrystal, P.W.; French, C.R.; Jean, F.; Havrylov, S.; van Baarle, S.; Peturson, A.-M.; Xu, P.; Crump, J.G.; Pilgrim, D.B.; Lehmann, O.J.; et al. The Axenfeld-Rieger Syndrome Gene FOXC1 Contributes to Left-Right Patterning. Genes 2021, 12, 170. https://doi.org/10.3390/genes12020170

Received: 24 December 2020

Accepted: 21 January 2021

Published: 26 January 2021

Publisher's Note: MDPI stays neutral with regard to jurisdictional claims in published maps and institutional affiliations.

Copyright: (c) 2021 by the authors. Licensee MDPI, Basel, Switzerland. This article is an open access article distributed under the terms and conditions of the Creative Commons Attribution (CC BY) license (https:// creativecommons.org/licenses/by/ $4.0 /)$.

\begin{abstract}
Precise spatiotemporal expression of the Nodal-Lefty-Pitx2 cascade in the lateral plate mesoderm establishes the left-right axis, which provides vital cues for correct organ formation and function. Mutations of one cascade constituent PITX2 and, separately, the Forkhead transcription factor FOXC1 independently cause a multi-system disorder known as Axenfeld-Rieger syndrome (ARS). Since cardiac involvement is an established ARS phenotype and because disrupted left-right patterning can cause congenital heart defects, we investigated in zebrafish whether foxc1 contributes to organ laterality or situs. We demonstrate that CRISPR/Cas9-generated foxc1a and foxc1b mutants exhibit abnormal cardiac looping and that the prevalence of cardiac situs defects is increased in foxc $1 a^{-/-}$; foxc $1 b^{-/-}$homozygotes. Similarly, double homozygotes exhibit isomerism of the liver and pancreas, which are key features of abnormal gut situs. Placement of the asymmetric visceral organs relative to the midline was also perturbed by mRNA overexpression of foxc1a and foxc1b. In addition, an analysis of the left-right patterning components, identified in the lateral plate mesoderm of foxc1 mutants, reduced or abolished the expression of the NODAL antagonist lefty2. Together, these data reveal a novel contribution from foxc1 to left-right patterning, demonstrating that this role is sensitive to foxc1 gene dosage, and provide a plausible mechanism for the incidence of congenital heart defects in Axenfeld-Rieger syndrome patients.
\end{abstract}

Keywords: FOXC1; Axenfeld-Rieger syndrome; left-right patterning; zebrafish; LEFTY

\section{Introduction}

The establishment of left-right asymmetry represents a fundamental step in embryonic development. Despite substantial progress elucidating a proportion of the core players, the mechanisms remain incompletely defined. Consequently, syndromes where organs are aberrantly positioned are of particular interest to geneticists and developmental biologists. In humans, the heart's normal anatomical position is left of midline, with a larger left ventricle designed for systemic circulation. The right lung has three lobes, while the left lung has two lobes and contains an indentation, the cardiac notch, allowing space for the heart. Furthermore, the stomach and liver are positioned left and right of the midline, respectively. This normal arrangement is called situs solitus, while the complete reversal 
of normal organ situs (termed situs inversus) is surprisingly well tolerated [1]. Far more deleterious are partial situs defects, collectively known as heterotaxy [2], characterized by mis-patterning of visceral organs along the left-right axis. These are associated with congenital diseases of the heart, lungs, spleen, stomach, and liver [3-5] that may be particularly challenging to treat. Intriguingly, many heterotaxy-associated genes also cause isolated congenital heart defects (CHDs) [6], suggesting that a proportion of idiopathic CHDs may reflect unrecognized situs defects [2,7-9].

In vertebrates, the breaking of left-right symmetry is established around a structure known as the left-right organizer (LRO). In mouse, zebrafish, frog, and humans, asymmetric fluid flow, generated by motile monocilia projecting into the extracellular fluid of the LRO, leads to asymmetric gene expression patterns around the LRO [10-12]. Consequently, loss of flow or of the motile cilia results in situs defects in animal models and humans [12-15]. In many vertebrates, the output of the LRO first manifests as a decreased expression of DAND5 (also known as charon in zebrafish or Cerl2 in mouse), which normally represses the transforming growth factor beta (TGF- $\beta$ ) family member Nodal, a secreted morphogen that is transiently expressed on the left side of the embryo [16-18]. Nodal upregulates its own transcription as well as transcription of the homeobox domain transcription factor Pitx2 [19]. Despite asymmetric Nodal expression lasting only a matter of hours, murine Pitx2 expression persists in the left lung and cardiac tissue throughout organogenesis and into adulthood [19-23]. Pitx2 plays a critical role in the establishment of left-right asymmetry, and homozygous murine mutants display pronounced phenotypes. For example, at E12.5, murine Pitx2 homozygotes display cardiac situs defects and right pulmonary isomerism (identical lobar anatomy of the left and right lungs) [22], while second heart field-specific Pitx2 mutations cause severe cardiac outflow tract defects [24]. In patients, heterozygous PITX2 mutations cause Axenfeld-Rieger syndrome (ARS); however, despite multi-organ involvement, organ situs defects have not been observed [25-28]. This likely reflects patients' heterozygous variants, compared with homozygous deletion of Pitx2, that can be achieved either globally or in the secondary heart field of murine models $[22,24]$.

Precise control of left-right patterning relies on the establishment of a signaling barrier to separate left- and right-specific gene expression programs. Critical components of the midline barrier are the TGF- $\beta$ family members Lefty1/2 [29-32] that are expressed in the midline and on the left side and diffuse to the midline and right side to inhibit Nodal signaling. Although both genes are expressed in the same region, the increased diffusion of Lefty proteins (relative to Nodal) limits Nodal target gene activation on the right side of the embryo [10,33]. Consequently, mice with a deletion in the Lefty2 enhancer that is activated by Nodal display left isomerism [34] while variants in LEFTY1/2 are associated with congenital heart defects [35]. Illustrating significant additional complexities in the control of left-right patterning, pathways initiated on the right side of the embryo have also been shown to contribute to organ laterality, as demonstrated by bone morphogenetic protein (BMP)-dependent activation of Prrxla in cardiac laterality and the role of hyaluronan in determining midgut laterality [36,37].

Axenfeld-Rieger syndrome (ARS) is an autosomal dominant condition caused by mutation and copy number variation of PITX2 and FOXC1 [26,28,38-43]. The ARS phenotypic spectrum includes ocular anterior segment dysgenesis, early-onset glaucoma, craniofacial dysmorphism, cerebral small vessel disease, cerebellar vermis hypoplasia, and hydrocephalus [26,44-47]. Despite no reported association with laterality defects, congenital heart defects are present in ARS, and these include atrial and ventricular septal defects, valve stenosis, and persistent truncus arteriosus [26,48-52], particularly associated with FOXC1 mutation [25-27,53]. Murine Foxc1 mutants also exhibit CHDs, but no alteration of L-R patterning has been reported [54-56].

To test the hypothesis that Foxc1 is a regulator of L-R patterning, we mutated the two zebrafish paralogs via clustered regularly interspaced short palindromic repeats (CRISPR)/Cas9 editing. In addition to replicating many of the ARS-associated phenotypes 
observed in human FOXC1 mutation, this strategy yielded evidence for a requirement for zebrafish foxc1a/b in establishing cardiac and gut laterality. Analysis of these zebrafish mutants also established that the expression of lefty 2 was altered. Our data thus provide the first evidence of a contribution by Foxc1 to left-right patterning.

\section{Materials and Methods}

\subsection{Zebrafish Lines and Husbandry}

Zebrafish lines were kept in accordance with the University of Alberta's Animal Care and Use Committee guidelines. Animal care protocols were approved by the University of Alberta Biosciences Animal Care Committee with protocol number 00000082. Experiments were performed in the $\mathrm{AB}$ line, and foxc $1 a^{\text {ua1017 }}$ and $f_{0} x_{c} 1 b^{\text {ua1018 }}$ were generated and maintained on the $\mathrm{AB}$ background. The $\operatorname{Tg}(\operatorname{sox} 10: \mathrm{GFP})^{\mathrm{ba} 4}$ line was used for examination of the craniofacial deformities caused by foxc1 mutation [57]. Zebrafish embryos were raised at $28.5^{\circ} \mathrm{C}$ or $33^{\circ} \mathrm{C}$ in E3 media or E3/0.2 mM 1-phenyl-2thiourea (PTU) from $22 \mathrm{~h}$ post fertilization (hpf) onwards to prevent pigmentation [58]. Standard staging of embryos was conducted as in Kimmel et al. 1995 [59]. foxc1 $a^{\mathrm{el} 542}$ and $f_{0} x c 1 b^{\mathrm{el} 620}$ have been previously described [60].

\subsection{Bioinformatics}

ENSEMBL sequences (human ENSG00000054598 and ENSG00000176692; mouse ENSMUST00000062292 and ENSMUST00000054691, xenopus ENSXETG00000000594 and ENSXETG00000016387, and zebrafish ENSDARG00000091481 and ENSDARG00000055398) were aligned with Clustal Omega for sequence conservation analysis. The synteny of human and zebrafish FOXC1 orthologs were investigated in ENSEMBL using the "region in detail" options to explore the chromosomal regions surrounding each gene, and schematics were generated in Corel Draw.

\subsection{LRO Cilia Length Measurements}

Embryos raised at $33{ }^{\circ} \mathrm{C}$ were collected at the 10 ss and fixed overnight at $4{ }^{\circ} \mathrm{C}$ in $4 \%$ paraformaldehyde (PFA). Storage at $-20^{\circ} \mathrm{C}$ in $100 \%$ methanol was usually performed for up to two weeks. Once transferred into phosphate buffered saline-tween 20 (PBS-T), embryos were dechorionated and blocked in 10\% heat-inactivated goat serum and $1 \%$ bovine serum albumin for $1 \mathrm{~h}$ while rocking. Primary antibody (monoclonal anti-tubulin, acetylated-Sigma, St. Louis, MO, USA, T6793) at 1:1000 dilution was performed overnight at $4{ }^{\circ} \mathrm{C}$. Embryos were washed $(3 \times 30 \mathrm{~min}$ PBS-T), and then, secondary antibody (goat anti-mouse Alexa Fluor ${ }^{\circledR}$ 555-Abcam, Cambridge, UK, ab150114) at 1:2000 and a nuclear counterstain (TO-PRO ${ }^{\mathrm{TM}}$-3 Iodide ThermoFisher Scientific, Waltham, MA, USA, T3605) at 1:2000 was performed for $2 \mathrm{~h}$ before $3 \times 15 \mathrm{~min}$ PBS-T washes and a final PBS-T wash overnight at $4{ }^{\circ} \mathrm{C}$ while rocking. Embryos were transferred into $70 \%$ glycerol via gradient $(30 \%, 50 \%$, and $70 \%)$, and the posterior region of the embryo including the LRO was excised with forceps and mounted in a slide viewing chamber and covered with a coverslip. The remainder of the embryo was processed for gDNA extraction. Imaging stacks through the whole LRO were performed on an LSM 700 confocal microscope (Zeiss, Oberkochen, Germany) using a $40 \times$ oil lens with a $1 \mu \mathrm{m}$ Z-interval. Maximum intensity projections were generated, and axonemal length for each cilium was calculated in FIJI, with the average cilia length per LRO per embryo being used for statistical analysis.

\subsection{Bead Tracking}

Left-right organizer function was assayed as described in [61]. Embryos at the 11$12 \mathrm{hpf}$ were dechorionated and embedded in a few drops of $1 \%$ low melting point agarose before the LRO was injected with approximately $0.5 \mathrm{~nL}$ of Fluoresbrite Polychromatic Red 0.5 Micron Microspheres (Polysciences, Warrington, FL, USA, \#19507). Bead flow was recorded for $10 \mathrm{~s}$ at $20 \times$ differential interference contrast on an Axioskop 2 microscope 
(Zeiss, Oberkochen, Germany) using QCapture Plus. FIJI software using the Manual Tracker plug-in was used to produce the bead projections and record metrics.

\subsection{In Situ Hybridization}

In situ hybridization was performed essentially as described in [62]. Briefly, digoxigeninlabelled probes were synthesized from linear DNA templates using RNA polymerase and digoxigenin-UTP kits (Roche, Basel, Switzerland) and were purified using SigmaSpin columns (Sigma, St. Louis, MO, USA). Fixed embryos were permeabilized with proteinase $\mathrm{K}$ treatment for $3 \mathrm{~min}$ (18-20 hpf) or $15 \mathrm{~min}$ (48 hpf), re-fixed with 4\% PFA for $20 \mathrm{~min}$, and hybridized with 1:200 RNA probes overnight at $65^{\circ} \mathrm{C}$. High stringency washes in $0.2 \times$ and $0.1 \times \mathrm{SSC} / 0.1 \%$ Tween 20 were carried out at $65^{\circ} \mathrm{C}$ for $20 \mathrm{~min}$ each, and blocking was performed for $1 \mathrm{~h}$ in $2 \%$ sheep serum and $2 \mathrm{mg} / \mathrm{mL}$ bovine serum albumin. Antidigoxigenin-AP antibody (Roche, Basel, Switzerland) at 1:5000 dilution was used to detect probe hybridization, and NBT/BCIP (Roche, Basel, Switzerland) coloration reactions were performed at $33^{\circ} \mathrm{C}$ until the signal was saturated. In situs were imaged by dissection light microscopy, and then, the tissue was genotyped. The probes used were myl7 [63]; foxa3 [64]; pitx2c and elvol6 [65]; foxc1a and foxc1b [66]; spaw fwd: ATGCAGCCGGTCATAGC, rev: TCAATGACAGCCGCACTC; lefty1 fwd: ATATTCTGACACGACACGTC, rev: CTGAAATATTGTCCATTGC; and lefty2 fwd: ATCAAGTACTCGGACACC, rev: GGAGTCCCATAACTGTG.

\subsection{Light Microscopy}

Live imaging was performed on PTU-treated embryos anesthetized in $0.6 \mathrm{mM}$ Tricaine (Sigma, St. Louis, MO, USA, Cat.\# A-5040) as per [67]. Both live imaging and in situ processed embryos were imaged on a 1\% agarose coated dishes using a SZX12 light microscope (Olympus, Tokyo, Japan) with QCapture Suite Plus. White balance and brightness/contrast editing were performed in Adobe ${ }^{\circledR}$ Photoshop ${ }^{\circledR}$ and were performed consistently between all genotypes and conditions.

\section{7. mRNA Overexpression and Morpholino Microinjection}

Capped mRNA was generated from a linear DNA template in a pCS2+ vector using the mMessage mMachine (ThermoFisher Scientific, Waltham, MA, USA) kit, purified using TRIzol ${ }^{\mathrm{TM}}$ (ThermoFisher Scientific, Waltham, MA, USA) and microinjected into the one-cell stage embryo at doses of 5, 15, and $75 \mathrm{pg}$. The highest $75 \mathrm{pg}$ dose was used for all subsequent experiments unless otherwise stated. All RNA technical replicates were performed on a single day, injecting foxc1 transcripts and control RNA at the same dose into the same clutch of embryos. Morpholino oligonucleotides foxc $1 a-$ CCTGCATGACTGCTCTCCAAAACGG—and foxc1b - GCATCGTACCCCTTTCTTCGGTA CA-were previously reported [46].

\subsection{Organ Situs Scoring}

Cardiac situs scoring was performed by light microscopy on live $48 \mathrm{hpf}$ embryos. While still in the chorion, embryos were anesthetized and rolled with fine watchmaker's forceps so they could be viewed ventrally. The sequential atrial-ventricular heart contractions allowed for the cardiac situs to be easily scored based on looping of the ventricle in comparison to the atrium. To assess gut situs, in situ hybridization on $48 \mathrm{hpf}$ embryos was performed using a foxa 3 probe, and once developed, the images of each embryo were recorded. Scoring of heart and gut situs were performed in a masked manner, and subsequently, the tissue was processed for gDNA extraction.

\subsection{Rhodamine-Conjugated Dextran Injections}

Hydrocephalus was examined in zebrafish embryos as in Lowery et al. [68]. Briefly, Texas Red Dextran (10,000 MW) (Life Technologies D1828) was dissolved to $5 \mathrm{mg} / \mathrm{mL}$ in Danieau Buffer $\left(17.4 \mathrm{mM} \mathrm{NaCl}, 0.21 \mathrm{mM} \mathrm{KCl}, 0.12 \mathrm{mM} \mathrm{MgSO}_{4} \cdot 7 \mathrm{H}_{2} \mathrm{O}, 0.18 \mathrm{mM} \mathrm{Ca}\left(\mathrm{NO}_{3}\right)_{2} \cdot 4 \mathrm{H}_{2} \mathrm{O}\right.$, and 
$1.5 \mathrm{mM}$ HEPES). The embryos were anesthetized in $0.1 \mathrm{mg} / \mathrm{mL}$ Tricaine (Sigma, St. Louis, MO, USA), embedded in 1.5\% low-melting point agarose (Millipore, Burlington, VT, USA, A9414), and injected with $4 \mathrm{~nL}$ Dextran into the hindbrain ventricle. The embryos were immediately recovered from agarose and imaged no longer than 5 min after injection on a dissection microscope by brightfield and fluorescence. The images were overlayed in Adobe Photoshop to produce figures.

\subsection{Genotyping}

Embryonic tissue was dissociated in $50 \mathrm{mM} \mathrm{NaOH}$ as in [69] and then diluted 1:10 before being used as template for PCR. Both foxc1 mutations were resolved via standard PCR genotyping: foxc1a fwd: TTCTTCGCCAGCTGTACG, rev: AATAACTTTGGTCGCTGC and foxc $1 b$ fwd: CCGTGTCTAGCCAAAGC, rev: TCGGATGAGTTTTGGATG. Gel electrophoresis was used to resolve the wildtype (WT) and mutant bands under the following conditions: foxc $1 a$ - sodium borate buffer, $3 \%$ agarose, $300 \mathrm{~V}$ for $1 \mathrm{~h}$ (as in [70]), foxc $1 b-$ Tris-acetate-EDTA buffer, $2 \%$ agarose, $150 \mathrm{~V}$ for $1 \mathrm{~h}$.

\subsection{Statistical Analysis}

Situs scoring of the heart and gut from foxc1 mutants was categorical data so Fisher's exact test was performed comparing normal and abnormal frequency between mutants and the WT control. The embryos from at least five clutches of embryos were scored and pooled for our analysis. For both mRNA overexpression and morpholino knockdown, the percentage of situs abnormalities was calculated per technical replicate (a clutch of embryos injected with the mRNA or MO). The mean percentage situs was compared via ANOVA with Dunnett post hoc test to determine which categories were significantly different. All graphs and statistics were performed in GraphPad Prism 8.

\section{Results}

\subsection{Generation of foxc1a and foxc1b Zebrafish Mutants}

Zebrafish possess two orthologs of human FOXC1 (foxc1a and foxc1b) but lack a FOXC2 ortholog [71]. While it has been suggested that zebrafish foxc1b may represent a functional ortholog of human FOXC2 [66], the amino acid sequences of Foxc1a and Foxc1b are more similar to human FOXC1 (identities: 74\% and 68\%, respectively) than FOXC2 (55\% and 53\%) (Table S1), with equivalent results when comparing the DNA-binding Forkhead domains (FOXC1: $97 \%$ and $97 \%$, and FOXC2: $93 \%$ and $93 \%$ ). Since the zebrafish paralogs possess conserved synteny with human FOXC1 (Figure S1) as well as similar protein sequences and overlapping expression [66,71], we anticipated compensatory activity with loss of a single paralog. To address this, we generated mutations in both foxc1a and foxc $1 b$ using CRISPR/Cas9 mutagenesis. The foxc1 $a^{\text {ua1017 }}$ allele is a 7 nucleotide deletion that is predicted to cause a premature stop codon after 39 amino acids (c.29_35del; p.Pro10Serfs*39). The foxc $1 b^{\text {ua1018 }}$ allele is a 40 nucleotide deletion that results in a premature stop codon after 28 amino acids (c.57_96del; p.Ile19Metfs*28) (Figure 1A-C). These are hereafter referred to as foxc $1 a^{-/-}$and foxc $1 b^{-1-}$.

The novel foxc1a $a^{-/-}$and foxc1 $1 b^{-/-}$mutations lie upstream of the Forkhead DNAbinding domain and result in frameshifts that are predicted to result in loss of $>90 \%$ of the encoded protein (Figure 1B). Consistent with the known mechanisms of non-sense mediated decay [72-74], we do not observe degradation of mRNA in either foxc1 $1 a^{-/-}$or foxc $1 b^{-/-}$homozygotes (Figure S2). Although the multiple methionine residues located between these mutations and the highly conserved Forkhead domain have the potential to function as alternative start sites (Figure S3), both mutations occur in the N-terminal transactivation domain where even small deletions profoundly reduce FOXC1 activity [75]. Furthermore, our novel mutations overlap previously published foxc1 null mutations (el542, el543, and el620 [60]) and phenocopy loss-of-function mutations in the Forkhead box DNA-binding domain [76]. For these reasons, we believe that the novel foxc1 mutations provide good models for foxc1 loss-of-function. 


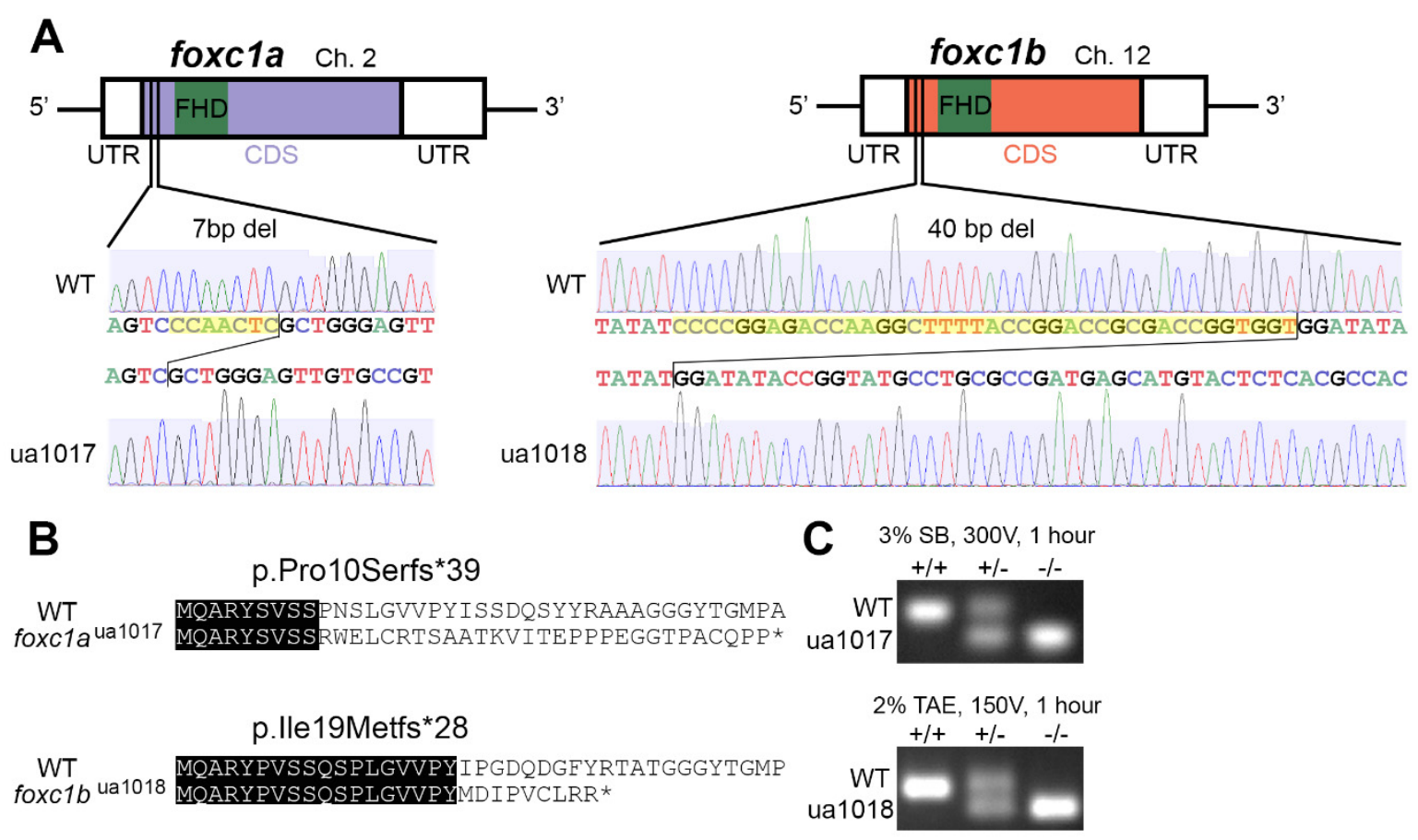

Figure 1. Allelic consequence of foxc1-targeted CRISPR/Cas9 mutagenesis: (A) a schematic representation of $f \circ x c 1 a^{\text {ua1017 }}$ and foxc $1 b^{\text {ua1018 }}$ mutations, with 7 and 40 base pair deletions (yellow highlighting) upstream of the DNA-binding Forkhead domain; (B) the predicted sequences of the first 40 amino acids translated from wildtype (WT) and mutant proteins with sequence identity (black highlighting), where the foxc1 $a^{\text {ua1017 }}$ allele produces a truncated 39-residue protein with loss of sequence homology from amino acid 10 and the foxc $1 b^{\text {ua1018 }}$ allele produces a truncated 28-residue protein with loss of sequence homology from amino acid 19; and (C) PCR genotyping from the gDNA template resolving the respective deletions in foxc1a and foxc1b. (FHD, Forkhead domain; UTR, untranslated region; CDS, coding sequence.).

\section{2. foxc1a Single and Double Mutants Display Gross Developmental Defects}

foxc1 $a^{+/-}$zebrafish are viable and fertile as heterozygotes and generate Mendelian ratios of larvae when incrossed. However, foxc $1 a^{-/-}$homozygotes do not live beyond 7 days post fertilization (dpf) and display obvious developmental defects by $96 \mathrm{~h}$ post fertilization (hpf; Figure 2A-F). Blood flow is observed until $72 \mathrm{hpf}$ when there is pericardial oedema in $86 \%$ of embryos (Figure $2 \mathrm{C}$ ) that becomes more severe over time. Zebrafish foxc1 $1 a^{-/-}$homozygotes also display microphthalmia (Figure 2B,C and Figure S4) and intracranial hemorrhage (Figure 2D) at $72 \mathrm{hpf}$. foxc $1 a^{-/-}$homozygotes display craniofacial dysmorphism (59\%; Figure S5), which has been reported previously [60].

Zebrafish $f \circ x<1 b^{-/-}$homozygotes are viable as larvae, survive to adulthood, and are fertile with no observable phenotype (results consistent with other studies $[60,66]$ ). Incrossing two foxc $1 b^{-/-}$homozygous adults to generate maternal zygotic foxc $1 b^{-/-}$ homozygote offspring also generated viable embryos indistinguishable from wildtype controls. Prior research on the zebrafish foxc $1 b^{-/-}$determined that it is a loss-of-function allele [77]. To investigate the potential for genetic compensation, we next examined the expression patterns of foxc $1 a$ and foxc $1 b$ during early development. Both foxc 1 mRNAs are maternally inherited as evidenced by in situ hybridization patterns at the 1 and 8 cell stages (Figure S6). During epiboly, the foxc1 expression patterns overlapped in the presumptive segmental plate and in the segmental plate and head mesenchyme during segmentation stages, albeit more weakly for foxc $1 b$. Finally, at the 18 somite stage (ss), foxc1 paralog expression was greatest in the periocular mesoderm, pharyngeal arch, and segmental plate. foxc1a expression was also observed in the sprouting intersegmental vessels. 

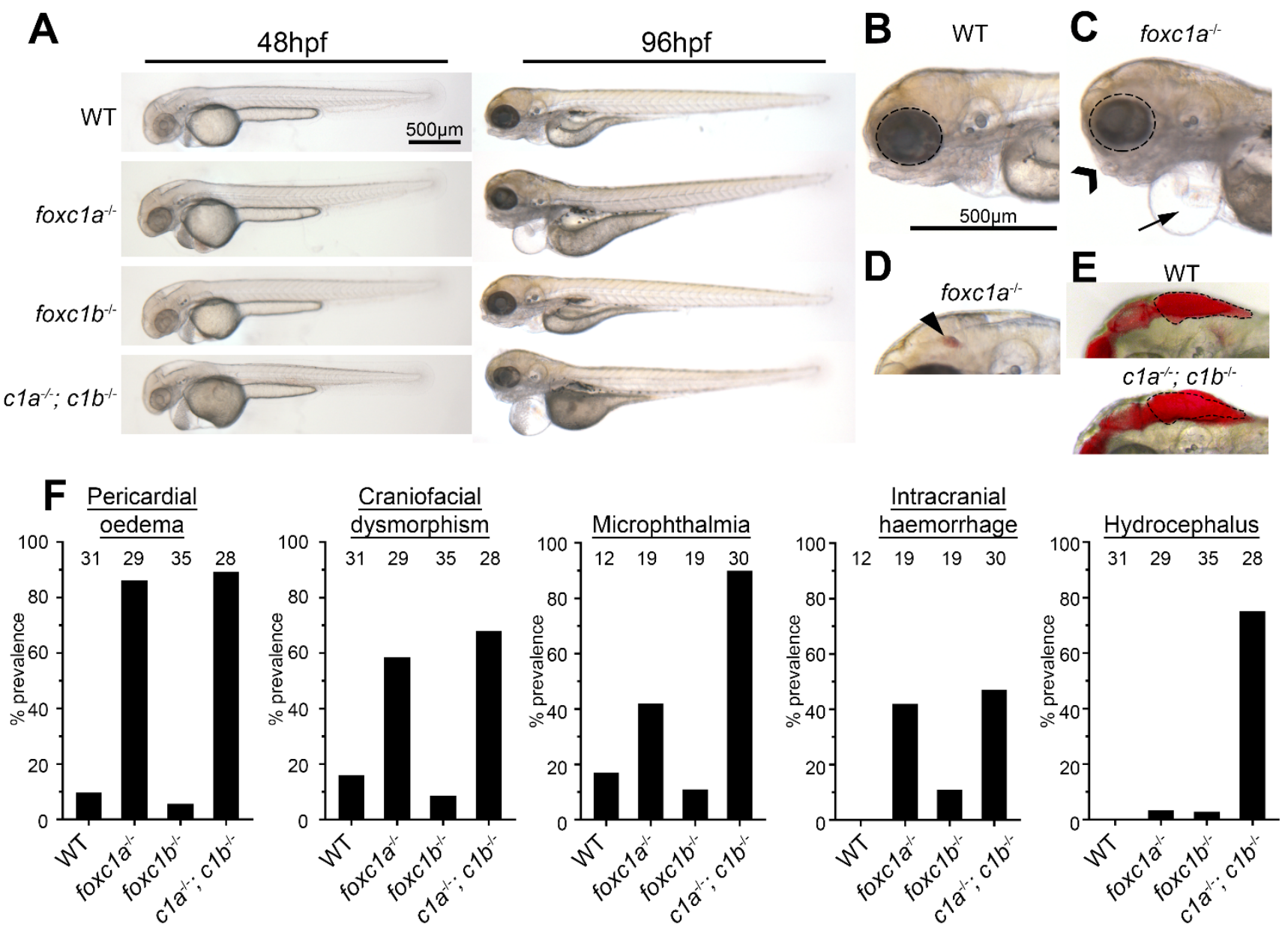

Figure 2. Foxc1 mutants exhibit multiple developmental defects. (A) foxc1 single mutants are largely indistinguishable from WT (wildtype) controls at $48 \mathrm{hpf}$ (left panels), whereas foxc1 $a^{-/-}$; foxc $1 b^{-/-}$double homozygotes display hydrocephalus and oedema. By $96 \mathrm{hpf}$, no changes are observed in foxc1 $1 b^{-/-}$homozygotes, however; foxc $1 a^{-/-}$homozygotes and foxc1 $a^{-/-}$f foxc $1 b^{-/-}$double homozygotes display pericardial oedema (compare $\mathbf{B}$ and $\mathbf{C}$, as highlighted by the arrow), microphthalmia (dotted circle), and craniofacial dysmorphism (chevron). At this stage, a subset of mutants also displayed intracranial hemorrhage (arrowhead in panel D), with $f o x c 1 a^{-/-}$homozygotes having greater frequency than $f o x c 1 b^{-/-}$ homozygotes ( $42 \%$ vs. $11 \%$, respectively), and (E) foxc1 $a^{-/-}$; foxc $1 b^{-/-}$double homozygotes present with hydrocephalus. (F) Quantification reveals that these defects are incompletely penetrant and generally more prevalent in double than single homozygotes (the number of embryos analyzed is shown above each bar). In the case of hydrocephalus, only the double homozygotes display an appreciable frequency of this phenotype.

Considering the substantial overlap in expression patterns, we generated a double foxc1a/foxc $1 b$ mutant line to determine if the phenotype became more severe. Both double heterozygotes (foxc1 $a^{+/-}$; foxc $\left.1 b^{+/-}\right)$and fish with 3 mutant alleles $\left(\right.$ foxc $1 a^{+/-} ;$foxc $\left.1 b^{-/-}\right)$ were viable as adults and were fertile. Crossing two double heterozygotes generated double mutant homozygote larvae ( foxc $1 a^{-/-} ;$foxc $1 b^{-/-}$) at expected Mendelian ratios, although developmental deformities were severe, especially with regards to microphthalmia and hydrocephalus (Figure 2E,F). Eighty-nine percent of $f o x c 1 a^{-/-}$; foxc1 $1 b^{-/-}$double homozygotes displayed pericardial oedema at $72 \mathrm{hpf}$, which suggest poor cardiac and/or pronephric duct function, at which time, $72 \mathrm{hpf}$ blood flow had also ceased. Craniofacial dysmorphism was observed in $68 \%$ of embryos and was more severe than single $f \circ x c 1 a^{-/-}$ homozygotes. Additionally, $75 \%$ of foxc $1 a^{-/}$; foxc $1 b^{-/-}$double homozygotes displayed hydrocephalus, which was absent in single mutants (Figure 2E,F). These data demonstrate that a loss of zebrafish foxc1a/b paralogs is generally more severe than single homozygosity and supports the hypothesis of genetic buffering by the two paralogs. 


\subsection{Alterations to foxc1 Gene Dosage Cause Visceral Organ Situs Defects}

Due to the loss of blood flow observed from $72 \mathrm{hpf}$ in foxc1a homozygotes, we next examined cardiac development in more detail. Loss of foxc1 resulted in significantly fewer embryos with normal D-looped hearts and increased the prevalence of abnormal O-looped (unlooped) and L-looped (situs inversus) hearts (Figure 3A). Homozygous foxc1a mutant hearts failed to loop in $31 \%$ of those examined ( $n=32, p=0.016)$, while homozygous foxc $1 b$ mutant embryos displayed an elevated prevalence of abnormal cardiac looping ( $23 \%$ O-loop and 5\% L-looped hearts; $n=39, p=0.036$ ). These findings are consistent with the overlapping expression patterns of the two genes and support a conserved function in patterning of cardiac situs. These results are directly supported by an analysis of cardiac looping in double foxc $1 a^{-/-}$; foxc $1 b^{-/-}$homozygotes, where $62 \%$ of foxc $1 a^{-/-} ;$foxc $1 b^{-/-}$ embryos have abnormal O-loops $(n=29, p<0.001)$.
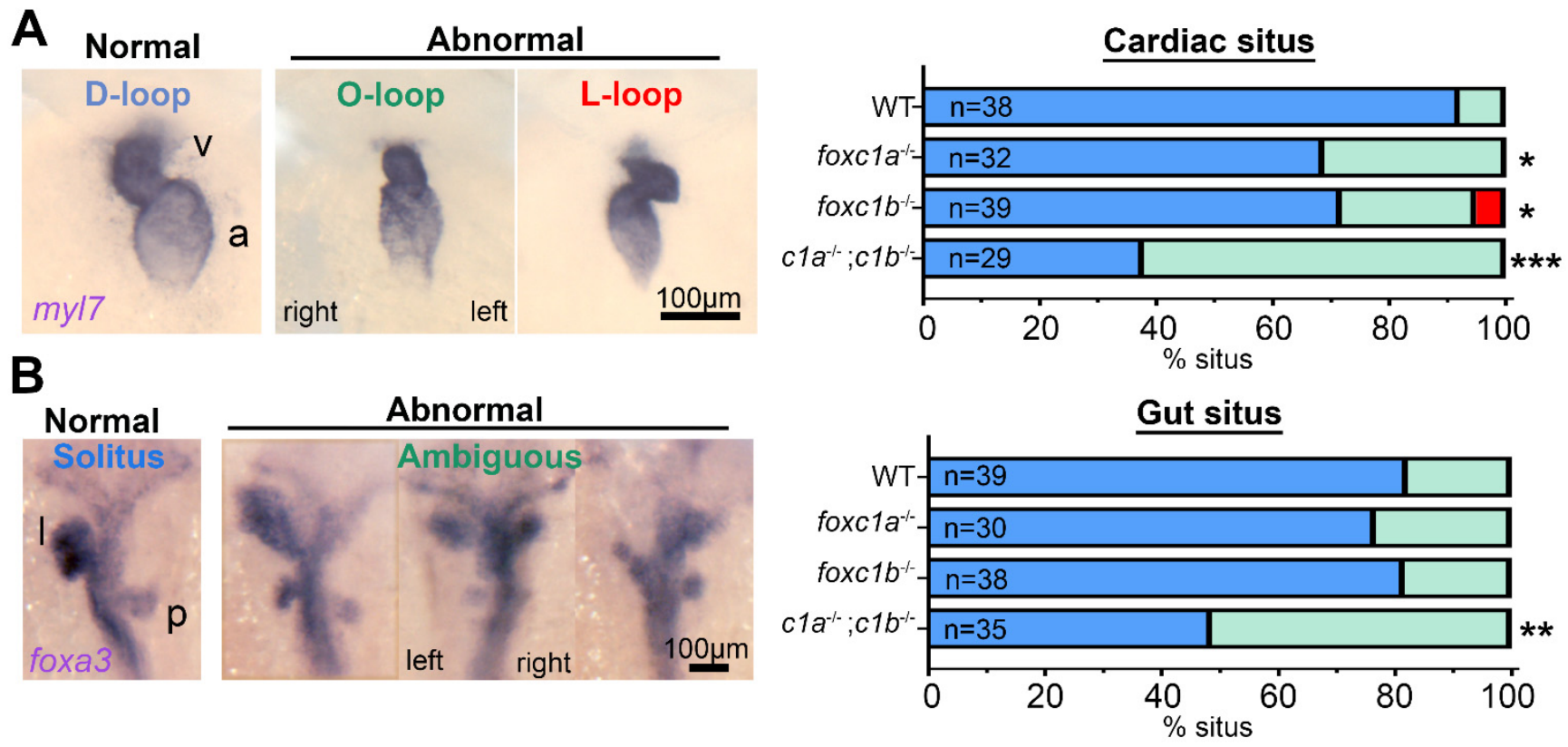

Figure 3. Decreased dosages of foxc1 result in multi-organ situs defects. (A) In situ hybridization with myl7 at $48 \mathrm{hpf}$ revealed aberrant cardiac situs (O-loop (green); L-loop (red)) compared with normal D-loop (blue). The prevalence of aberrant situs is increased in foxc1a, foxc1b, and double homozygotes $\left({ }^{*} p=0.016,{ }^{*} 0.036,{ }^{* *}<0.001\right.$ respectively, Fisher's exact test) when compared to WT siblings. (B) At the same stage, the normal arrangement (solitus, blue) of the gut is left-sided liver (l) and right-sided pancreas $(\mathrm{p})$; however, the incidence of abnormal (ambiguous, green) gut situs was significantly greater in double homozygotes (** $p=0.003$, Fisher's exact test).

To investigate whether the situs defects were cardiac specific or systemic, gut situs was assessed using the liver and pancreas expression domain of foxa3. Although neither foxc $1 a^{-/-}$nor foxc $1 b^{-/-}$homozygotes exhibited altered gut situs, this was present in $51 \%$ of foxc $1 a^{-1-}$; foxc $1 b^{-/-}$double homozygous embryos. In these, the most common phenotype was isomerism of the liver and / or pancreas (Figure 3B), and overall, these results suggest that cardiac situs is more sensitive to loss of foxc1 than gut situs.

Because FOXC1 function is exquisitely sensitive to gene dosage, with both gene duplication and deletion causing disease [25,41,42,78], we examined whether mRNA overexpression of foxc 1 induces cardiac situs defects (Figure 4). An injection of $75 \mathrm{pg}$ of either foxc1a or foxc $1 b \mathrm{mRNA}$ resulted in divergence from normal D-looped hearts observed in $45 \%$ of foxc $1 a$ and $38 \%$ of foxc $1 b$ mRNA-injected embryos, with the prevalence greatly increased from the mCherry mRNA control (Figure 4A-C). Such cardiac situs defects were observed in a dose-dependent manner (Figure 4D), and hydrocephalus commonly arose at $72 \mathrm{hpf}$ in embryos when either foxc1a or foxc1b was overexpressed (Figure S7). Gut situs 
was similarly affected (Figure 4E), with a comparable prevalence of abnormal gut situs observed (foxc1a overexpression: $53 \%$, foxc1b 31\%, mCherry control $3 \%, p=0.02$ ).

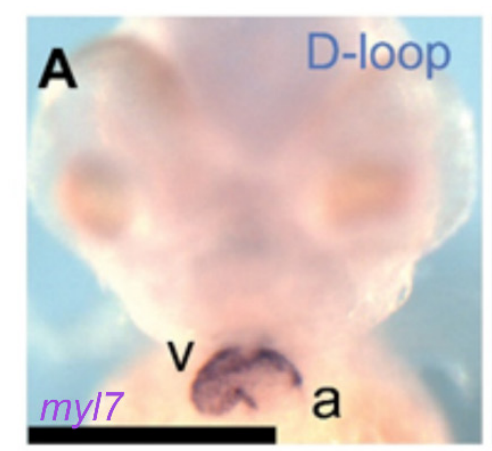

D Cardiac Looping Situs
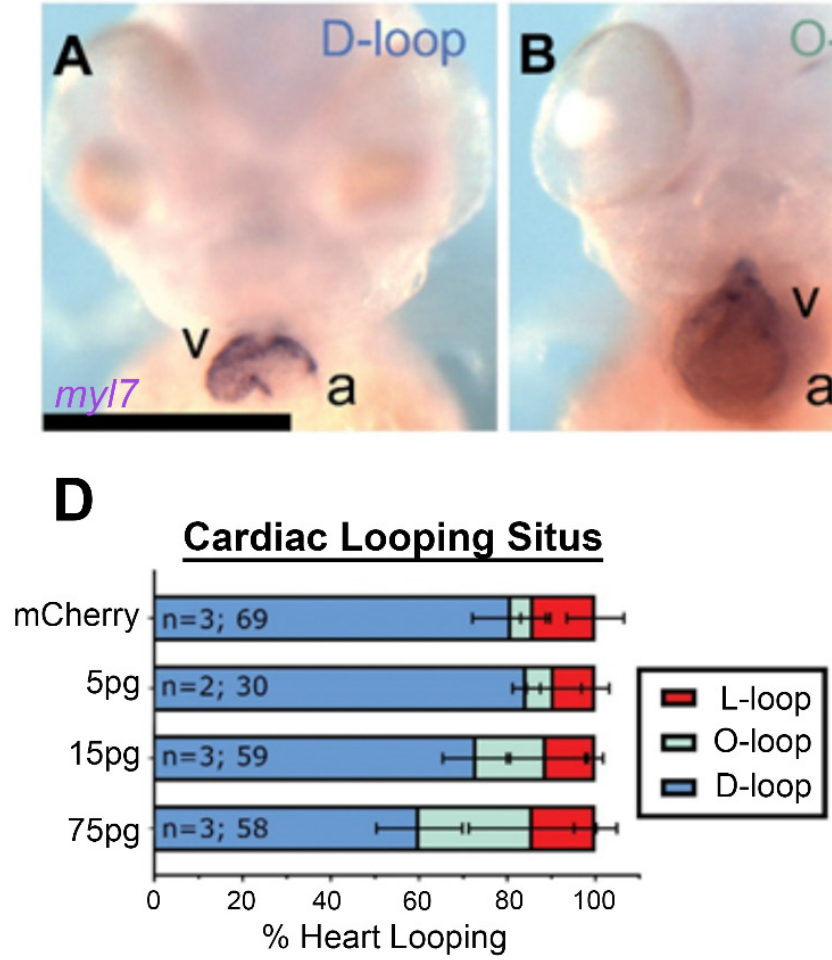

a

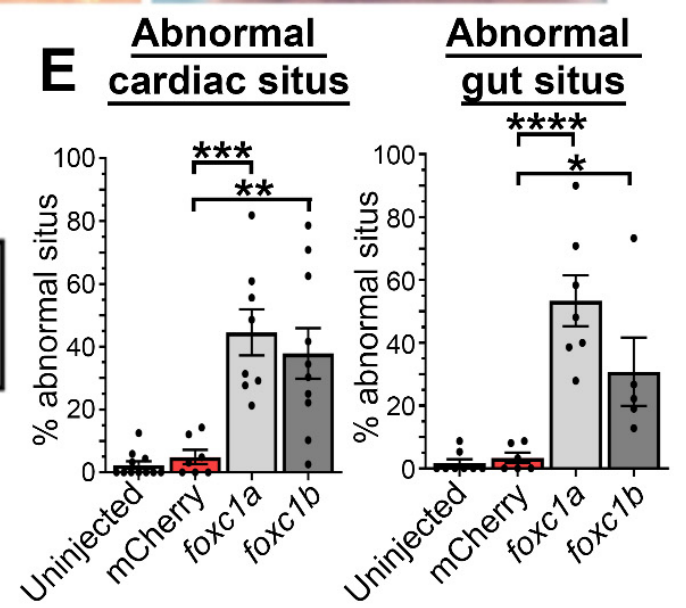

Figure 4. Foxc1a mRNA overexpression causes cardiac situs defects in a dose-dependent manner: (A-C) myl7 in situ hybridization of $75 \mathrm{pg}$ foxc1a mRNA-injected embryos at $48 \mathrm{hpf}$, with representative images of the three cardiac looping morphologies provided (v, ventricle; a, atrium); (D) quantification of cardiac situs in control and foxc1a mRNA-injected embryos revealing an increasing prevalence of anomalous cardiac looping with increasing amounts of foxc $1 a$ mRNA; and (E) quantification of embryo situs defects in embryos injected with $75 \mathrm{pg}$ of foxc1a mRNA. Statistical significance was apparent in comparisons between foxc1a/b and mCherry controls (cardiac: $p=0.0002$ and 0.0012; gut: $p<0.0001$ and 0.0205 . mCherry vs. foxc1a and foxc1b respectively. One-way ANOVA and Dunnett's post hoc test. ${ }^{*} p<0.05,{ }^{* *} p<0.01,{ }^{* * *} p<0.001$, $* * * * p<0.0001)$.

Although these data support a requirement for foxc1 in normal organ situs determination in zebrafish and were supported by morpholino knockdown (Figure S8), this finding ran counter to conventional understanding of the role of Foxc1. Therefore, to validate these results, we assayed independently generated zebrafish alleles [60] and demonstrate that these foxc1 $a^{-/-}$; foxc $1 b^{-/-}$double homozygotes exhibit similar cardiac and gut situs defects (Figure S9).

\subsection{Loss of foxc1a/b Does Not Disrupt LRO Fluid Flow}

The left-right organizer (LRO) is a transient organelle that has been described in multiple vertebrate species, including zebrafish (Kupffer's vesicle), and is required for left-right axis patterning. foxj1-dependent motile cilia within the LRO generate leftward fluid flow to initiate left-right asymmetric gene expression of the lateral plate mesoderm. Accordingly, we next examined LRO cilia in single and double foxc1 zebrafish mutants

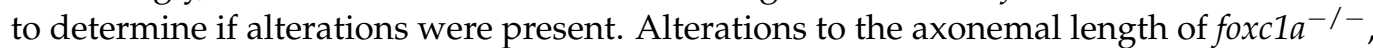
foxc $1 b^{-/-}$, and double foxc1 $1 a^{-/-}$; foxc1 $1 b^{-/-}$homozygotes (Figure $5 \mathrm{~A} ; 82 \%, 93 \%$, and $82 \%$ of WT respectively) did not reach statistical significance $(p=0.279)$. In order to determine if the loss of foxc1 in zebrafish instead impacted the biological function of LRO cilia, nodal flow was measured via fluorescent bead tracking. These experiments in 
foxc $1 a^{+/-}$heterozygous incrosses revealed comparable ciliary-driven counterclockwise flow in wildtype embryos, foxc $1 a^{-/-}$homozygotes, and foxc1a/b morphants (Figure 5B, $\mathrm{B}^{\prime}, \mathrm{B}^{\prime \prime}$ ). Together, these data suggest that loss of foxc $1 a / b$ does not appreciably alter LRO ciliary function. These findings are consistent with the absence of observable foxc1a or foxc $1 b$ expressions in the dorsal forerunner cells or LRO during gastrulation and segmentation stages, respectively (Figure S6).

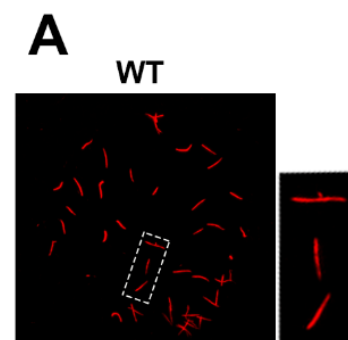

foxc1 $1 b^{-}$

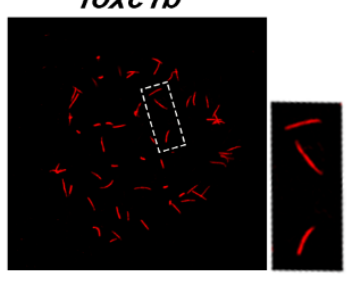

foxc1a $1 a^{-}$

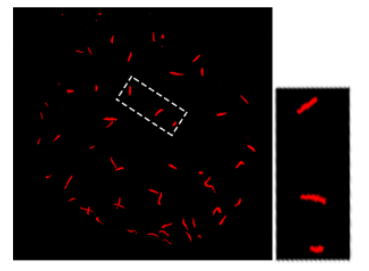

$c 1 a^{--} ; c 1 b^{-1}$

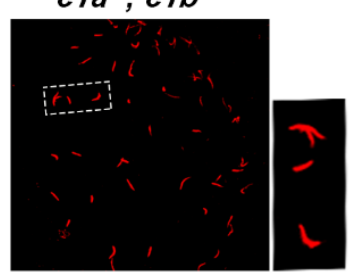

B

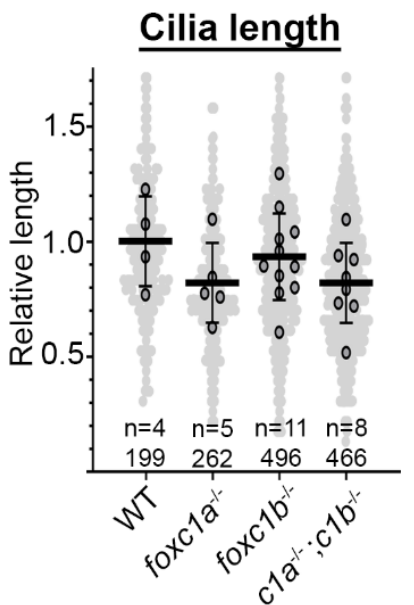

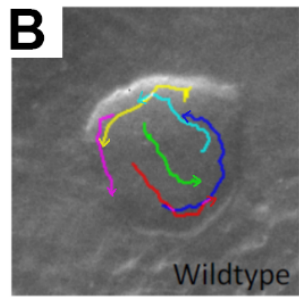
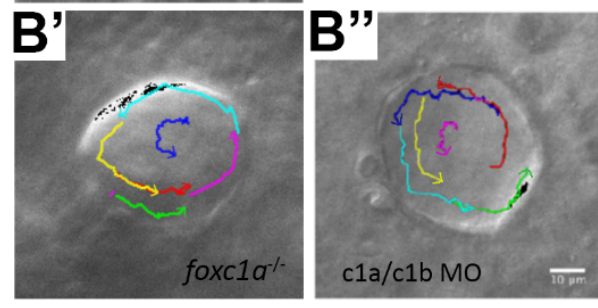

Figure 5. Loss of foxc1 does not significantly change cilia length or left-right organizer flow. (A) Acetylated $\alpha$-tubulin immunostaining of left-right organizer (LRO) cilia revealed that average cilia length was not significantly altered in foxc1 mutants $\left(\right.$ foxc $1 a^{-/-}, 82 \%$; foxc $1 b^{-/-}, 93 \%$; foxc $1 a^{-/-}$; foxc $1 b^{-/-}, 82 \%$ of WT length; $p=0.286$, ANOVA; $4-11$ embryos imaged per condition, all cilia per condition shown in light grey). Tracking of fluorescent bead flow in the LRO revealed unchanged counterclockwise flow between WT (B), foxc1 $a^{-/-}$homozygotes $\left(\mathbf{B}^{\prime}\right)$, and foxc1a/foxc1b morphants ( $\left.\mathbf{B}^{\prime \prime}\right)$.

\section{5. foxc1 Mutants Have Loss of lefty2 Expression in the Lateral Plate Mesoderm}

Since no changes at the level of the LRO were resolved, we next examined L-R axis determinants downstream of the LRO. The early L-R patterning gene southpaw (spaw), equivalent to mammalian Nodal, did not show altered expression patterns in foxc1 mutants (Figure 6A). In contrast, the Nodal antagonist lefty 2 was altered in the lateral plate mesoderm (Figure $6 \mathrm{~B}$ ): $33 \%$ of foxc $1 a^{-/-}$and $38 \%$ of $f \circ x \mathrm{C}^{-1-} \mathrm{a}^{-1}$; foxc $1 b^{-/-}$double homozygotes exhibited normal left-sided expression (Figure 6B). foxc $1 b^{-/-}$single mutants trended towards altered lefty 2 expression, with only $43 \%$ having normal left-sided expression, although they did not reach statistical significance $(p=0.061)$. This inconsistency in the roles of foxc $1 a$ and foxc $1 b$ in controlling lefty 2 expression may represent a divergence of protein function between the paralogs or alternatively be due to a lack of statistical power of our analysis. However, a consistent trend was observed with the independently generated foxc1 $1 a^{-/-}$; foxc1 $1 b^{-/-}$double homozygotes (Figure S9) [60]. These data suggest that the Foxc1 paralogs regulate expression of lefty 2 during establishment of the left-right axis, and consistently, the expression domains of both paralogs overlap the primitive heart fields (Figure S6), where lefty 2 is also expressed [79]. Furthermore, overexpression of both paralogs induced the loss of left-sided lefty 2 expression in approximately $83 \%$ of foxc $1 a$ and $77 \%$ of foxc $1 b$ embryos compared to $25 \%$ of mCherry control $25 \%$ ( $p=0.0007$ and 0.003 , respectively) (Figure 6C and Figure S10). Together, these data demonstrate that increased and decreased foxc1 expression perturb lefty 2 patterning. 
A
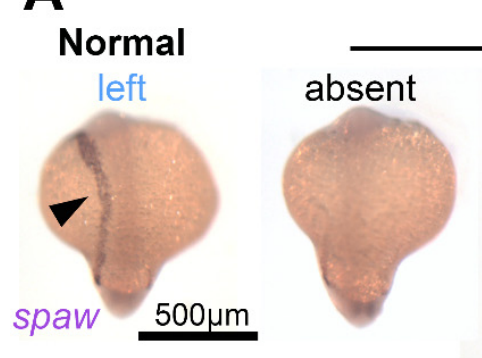

Abnormal
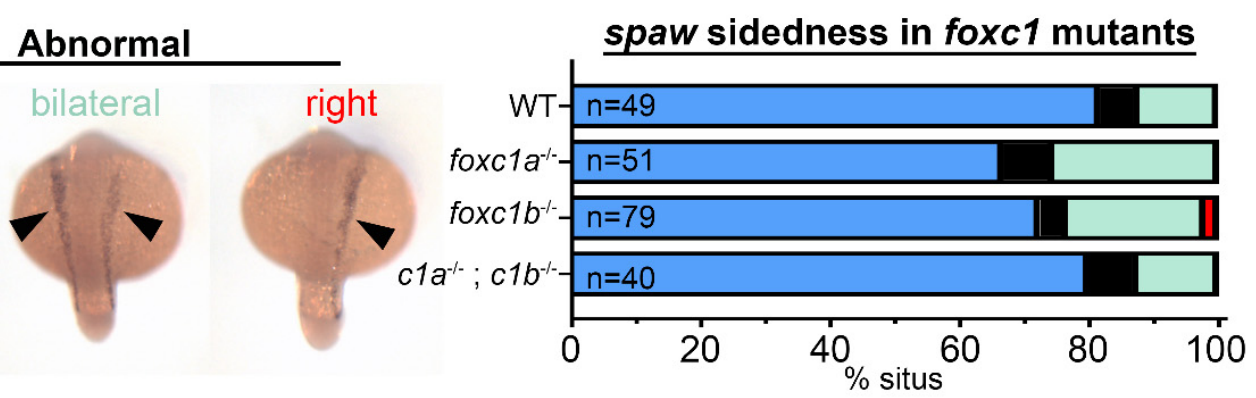

B
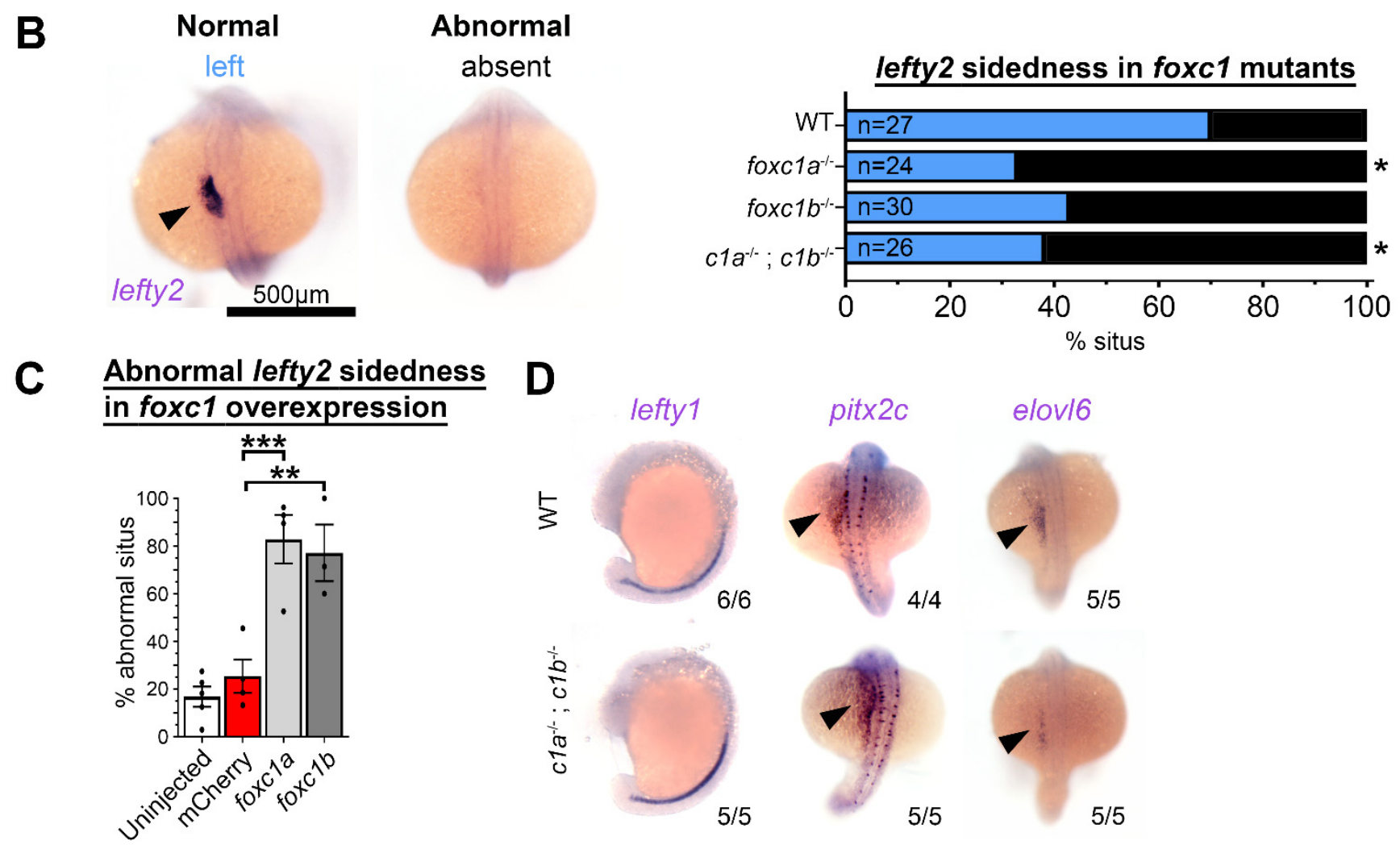

Figure 6. Foxc1 mutants display loss of lefty2 expression independent of changes to other left-right patterning genes. (A) In situ hybridization with southpaw (spaw) revealed no difference in the prevalence of normal left-sided expression (normal = blue, absent $=$ black, bilateral $=$ green, and right $=$ red) in foxc 1 mutants compared to controls $(p>0.1$, Fisher's exact test). (B) Conversely, lefty 2 expression was significantly altered in foxc1 mutants. Normal left-sided lefty 2 expression was absent more frequently in foxc $1 a^{-/-}$and double foxc $1 a^{-/-} ;$foxc $1 b^{-/-}$homozygotes $(p=0.012$ and 0.028 , respectively) and trended to be absent in foxc $1 b^{-/-}$homozygotes without reaching statistical significance $(p=0.061$, Fisher's exact test) (normal = blue and absent = black). (C) lefty2 expression was significantly abnormal, with the overexpression of foxc1a or foxc1b ( $p=0.0007$ and 0.0030, respectively, ANOVA and Dunnett's Test). (D) Analysis of the additional leftright patterning genes lefty 1 , pitx $2 c$, and elvol6 revealed no differences between WT, and foxc $1 a^{-/-}$; foxc $1 b^{-/-}$double homozygotes. $\left.{ }^{*} p<0.05,{ }^{* *} p<0.01,{ }^{* * *} p<0.001\right)$.

This finding of lefty 2 mis-expression led us to examine other genes required for the establishment of the left-right axis. Lefty 1 is a spaw antagonist closely related to Lefty 2 but is expressed in the embryonic midline. pitx2c is asymmetrically expressed in the left LPM and lies downstream of spaw. No changes to the expression of either gene were resolved in double homozygotes at the 22 ss or 18 ss respectively (Figure 6D). Finally, in situ analysis of elovl6, an enzyme asymmetrically expressed in lateral plate mesoderm that is responsive to LRO function $[65,80]$, revealed no changes in $f \circ x \mathrm{Ca}^{-/-} ;$foxc $1 b^{-/-}$double homozygotes at the 18 ss. These results suggest that Foxc1 regulates lefty 2 rather than induces loss or randomization of all left-right patterning gene expressions, as seen when LRO function is 
perturbed [81]. Loss of foxc1 may therefore be sufficient to perturb organ situs in a partially penetrant manner.

\section{Discussion}

Our findings expand the role of the Forkhead box transcription factor Foxc1 in a new direction by establishing a novel contribution to patterning of the vertebrate left-right body axis. Through CRISPR-Cas9 mutation of the zebrafish foxc1a and foxc1b paralogs, we demonstrate that loss of a single paralog induces cardiac situs defects. Consistently, mutation of both paralogs results in more extensive alterations to left-right patterning, with the involvement of multiple visceral organs evident from cardiac and gut situs defects in double homozygous foxc1 mutants. To our knowledge, this is the first report of single foxc $1 b^{-/-}$homozygotes possessing a phenotype. We also demonstrate that, unlike other FOX paralogs [82-84], a disruption of ciliogenesis was not the mechanism of action for organ situs in the foxc1 mutants. From a mechanistic perspective, we show that foxc1 mutation disrupts lefty 2 expression in the lateral plate mesoderm, findings recapitulated in independently generated foxc1 $a^{-/-}$; foxc $1 b^{-/-}$mutants. This perturbation of a key antagonist of left-sided identity, taken together with our other data, reveals a hitherto unappreciated role of foxc1 in regulating organ laterality and illustrates how analyses of foxc1a/b mutant zebrafish can inform studies of patients and murine loss-of-function ARS models.

Our novel zebrafish foxc1 mutations recapitulate many phenotypes observed in Axenfeld-Rieger syndrome (ARS) patients and animal models thereof $[46,47,85]$. By mutating both zebrafish orthologs of human FOXC1, we show that foxc1a/b homozygotes display craniofacial dysmorphism, cardiac defects, and intracranial hemorrhage. These phenotypes correlate closely with clinical data, where up to $43 \%$ of patients exhibit craniofacial anomalies [25], 11\% exhibit congenital heart defects [27], and 73\% exhibit white matter hyperintensities [46]. The absence of most phenotypes in foxc1 $1 b^{-/-}$homozygotes could suggest considerable genetic compensation and/or residual activity of the protein. Firstly, previous studies whereby foxc1b was knocked down via morpholino oligonucleotides failed to resolve a phenotype despite foxc1a knockdown resulting in microphthalmia, somitic delay, and intracranial hemorrhage $[46,66,86]$. Furthermore, foxc $1 b$ mutants have also been described without resolving a phenotype $[60,76]$. Our findings demonstrate that foxc $1 b$ is required for cardiac situs in isolation. Secondly, similar human mutations upstream of the Forkhead box DNA-binding domain are loss-of-function alleles that cause Axenfeld-Rieger syndrome $[38,42,87]$. Considering the significantly overlapping expression patterns of the foxc1 paralogs, it is unsurprising that genetic buffering is observed; this is evidenced by the presence of gut situs defects and an almost complete penetrance of hydrocephalus in foxc1 $a^{-/-}$; foxc1 $1 b^{-/-}$double homozygotes, which is lacking in both our foxc1a single mutants and those previously published [76]. Hydrocephalus specifically is a key phenotype of the murine Foxc1 $1^{-/-}$mutant "congenital hydrocephalus" and an occasional finding in patients with heterozygous FOXC1 mutation or deletion [27,38].

The Forkhead box transcription factor family is evolutionarily conserved from yeast to humans and comprises more than 45 members in mammals, each containing an 80100 amino acid winged-helix DNA-binding domain. Extensive links to development and disease have been established for many members of this family, and intriguingly, three FOX genes are recognized regulators of L-R patterning. Foxj1 is expressed in the highly ciliated choroid plexus, lung epithelium, oviduct, and testis [88], and Foxj1 knockout mice display loss of motile cilia and abrogation of left-right patterning. Foxj1 is thus recognized as a key regulator of motile ciliogenesis [83]. Foxa2 plays a role in promoting the expression of Pkd1l1 and is essential for forming the left-right organizer [89], while Foxh1 (also known as Fast) functions as a Smad co-factor downstream of Nodal signaling [90]. Two additional findings led us to examine a role for Foxc1 in visceral organ situs. First, congenital heart defects (frequently associated with heterotaxy) are present in heterozygous patients and Foxc1 knockout mice. Second, Pitx2, a protein that may directly bind Foxc1 [91], and also causes 
ARS in humans, is a critical regulator of left-right patterning. Our data demonstrate that foxc1 mutation induces situs defects of visceral organs, with two mutant copies required for cardiac situs defects, while four are needed for anomalous gut situs. One explanation for the appearance of gut situs defects only in double homozygotes is genetic buffering. Indeed, the expression patterns of the foxc1 paralogs largely overlap and some tissues tolerate the loss of Foxc1a as evidenced by the appearance of hydrocephalus only in $f \circ \mathrm{cc} 1 a^{-/-}$; foxc $1 b^{-/-}$homozygotes. Recapitulation of these phenotypes with independently generated mutants and mRNA overexpression of either foxc $1 a$ or foxc $1 b$ demonstrates that increases and decreases in the levels of these foxc1 paralogs impacts the situs of multiple visceral organs.

The establishment of left-right patterning can be divided into three separable phases: the creation of a ciliated epithelium that drives leftward fluid flow; the initiation of leftspecific Nodal-Pitx2 gene expression; and finally, the induction of a midline barrier that blocks Nodal activity from signaling on the right side. Our studies on Foxc1 demonstrate normal cilia-mediated flow in the LRO and proper initiation of left-specific spaw and pitx2c, consistent with Foxc1 playing a later role in regulating left-right axis formation. Indeed, when characterizing left-right isomerism defects in foxc1a/b mutants, we note that phenotypes are not consistent with a randomization of organ situs, as would have been expected from an early role in establishing left-specific gene expression. Furthermore, we find markedly perturbed lefty 2 expression in foxc $1 a / b$ mutants. Lefty proteins, which are known antagonists of Nodal (Spaw) signaling, have significantly greater rates of diffusion than the Nodal proteins that they antagonize [33]. This leads to the prevailing model for how Lefty functions as a midline barrier to block extracellular Nodal from reaching the right side of the embryo. Consistent with the observed heterotaxic effects on the left-right placement of heart, liver, and pancreas, we conclude that Foxc1 proteins play a key role in the regulation of lefty gene expression and are thus likely components of antagonistic control of the Nodal morphogen.

In this manuscript, we present the first evidence of foxc1 playing a role in left-right patterning of the lateral plate mesoderm and in controlling organ situs. These data have significant implications for understanding the etiology of Axenfeld-Rieger syndrome associated congenital heart defects and strengthens the case for cardiac screening in patients diagnosed with ARS. Our findings should also encourage a reexamination of organ situs in other Foxc1 models, since situs defects may be subtle and only partially penetrant. Since Foxc1 is the fourth Forkhead gene to participate in left-right patterning, this result emphasizes the gene family's importance in the control of organ situs and will encourage future studies to determine how multiple Forkhead family members evolved seemingly distinct roles in the establishment of the left-right body axis.

Supplementary Materials: The following are available online at https://www.mdpi.com/2073 $-4425 / 12 / 2 / 170 /$ s1, Figure S1: Syntenic analysis of the foxc1 paralogs. Figure S2: foxc1 mutations foxc1aua1017 and foxc1bua1018 does not induce nonsense mediated decay. Figure S3: The ua1017/ua1018 alleles are nonsense mutations overlapping previously published foxc1 null alleles. Figure S4: foxc1a mutants are microphthalmic. Figure S5: foxc1a mutants have defects in craniofacial cartilage. Figure S6: foxc1 expression during left-right patterning. Figure S7: Overexpression of foxc1a or foxc1b causes hydrocephalus. Figure S8: Morpholino knockdown recapitulates mutant situs phenotypes. Figure S9: Organ situs and left-right patterning defect trends in distinct alleles of foxc1 $a^{-/-} ;$foxc $1 b^{-/-}$. Figure S10: foxc1a and foxc1b overexpression result in absent lefty2 expression. Table S1: Both zebrafish Foxc1 protein sequences are orthologous to human FOXC1.

Author Contributions: Conceptualization, P.W.C., S.H., S.v.B., O.J.L., and A.J.W.; formal analysis, P.W.C., F.J., and A.-M.P.; funding acquisition, C.R.F., O.J.L., and A.J.W.; investigation, P.W.C., F.J., and A.-M.P.; methodology, P.W.C., A.-M.P., and A.J.W.; project administration, O.J.L. and A.J.W.; resources, P.W.C., C.R.F., P.X., and J.G.C.; supervision, J.G.C., D.B.P., O.J.L., and A.J.W.; validation, P.W.C.; visualization, P.W.C.; writing—original draft, P.W.C.; writing—review and editing, P.W.C., C.R.F., F.J., S.H., J.G.C., O.J.L., and A.J.W. All authors have read and agreed to the published version of the manuscript. 
Funding: Funding was provided by the Canadian Institutes of Health Research, and Women and Children's Health Research Institute (to O.J.L.), by a Heart and Stroke Foundation of Canada postdoctoral fellowship (to C.F.), by the Natural Sciences and Engineering Research Council of Canada (NSERC, RGPIN 2016-06482 to A.J.W.), by an NIH grant (DE027550 to J.G.C.), and by Bridge funding from Women and Children's Health Research Institute (to A.J.W.).

Institutional Review Board Statement: The study was conducted according to the guidelines of the Declaration of Helsinki and was approved by the University of Alberta Biosciences Animal Care Committee (protocol number 00000082).

Informed Consent Statement: Not applicable.

Data Availability Statement: Data is contained within the article or Supplementary Materials.

Acknowledgments: The authors thank Jeffrey Amack for providing the in situ hybridization probe templates and for his insight into the results early in the project; Sarah Hughes for access to her imaging suite; Casey Carlisle, Lance Doucette, and Nicole Noel for critical reading of the manuscript; and the Science Animal Support Services technicians at the University of Alberta.

Conflicts of Interest: The authors declare no conflict of interest.

\section{References}

1. Peeters, H.; Devriendt, K. Human laterality disorders. Eur. J. Med. Genet. 2006, 49, 349-362. [CrossRef] [PubMed]

2. Sutherland, M.J.; Ware, S.M. Disorders of left-right asymmetry: Heterotaxy and situs inversus. Am. J. Med. Genet. C Semin. Med. Genet. 2009, 151C, 307-317. [CrossRef] [PubMed]

3. Shiraishi, I.; Ichikawa, H. Human heterotaxy syndrome-From molecular genetics to clinical features, management, and prognosis. Circ. J. 2012, 76, 2066-2075. [CrossRef] [PubMed]

4. Taketazu, M.; Lougheed, J.; Yoo, S.J.; Lim, J.S.; Hornberger, L.K. Spectrum of cardiovascular disease, accuracy of diagnosis, and outcome in fetal heterotaxy syndrome. Am. J. Cardiol. 2006, 97, 720-724. [CrossRef] [PubMed]

5. Borenstein, S.H.; Langer, J.C. Heterotaxia syndromes and their abdominal manifestations. Curr. Opin. Pediatr. 2006, 18, $294-297$. [CrossRef]

6. Versacci, P.; Pugnaloni, F.; Digilio, M.C.; Putotto, C.; Unolt, M.; Calcagni, G.; Baban, A.; Marino, B. Some Isolated Cardiac Malformations Can Be Related to Laterality Defects. J. Cardiovasc. Dev. Dis. 2018, 5, 24. [CrossRef]

7. Ramsdell, A.F. Left-right asymmetry and congenital cardiac defects: Getting to the heart of the matter in vertebrate left-right axis determination. Dev. Biol. 2005, 288, 1-20. [CrossRef]

8. Francis, R.J.; Christopher, A.; Devine, W.A.; Ostrowski, L.; Lo, C. Congenital heart disease and the specification of left-right asymmetry. Am. J. Physiol. Heart Circ. Physiol. 2012, 302, H2102-H2111. [CrossRef]

9. Casey, B. Two rights make a wrong: Human left-right malformations. Hum. Mol. Genet. 1998, 7, 1565-1571. [CrossRef]

10. Nakamura, T.; Mine, N.; Nakaguchi, E.; Mochizuki, A.; Yamamoto, M.; Yashiro, K.; Meno, C.; Hamada, H. Generation of robust left-right asymmetry in the mouse embryo requires a self-enhancement and lateral-inhibition system. Dev. Cell 2006, 11, 495-504. [CrossRef]

11. Nonaka, S.; Tanaka, Y.; Okada, Y.; Takeda, S.; Harada, A.; Kanai, Y.; Kido, M.; Hirokawa, N. Randomization of left-right asymmetry due to loss of nodal cilia generating leftward flow of extraembryonic fluid in mice lacking KIF3B motor protein. Cell 1998, 95, 829-837. [CrossRef]

12. Noone, P.G.; Leigh, M.W.; Sannuti, A.; Minnix, S.L.; Carson, J.L.; Hazucha, M.; Zariwala, M.A.; Knowles, M.R. Primary ciliary dyskinesia: Diagnostic and phenotypic features. Am. J. Respir. Crit. Care Med. 2004, 169, 459-467. [CrossRef] [PubMed]

13. Supp, D.M.; Witte, D.P.; Potter, S.S.; Brueckner, M. Mutation of an axonemal dynein affects left-right asymmetry in inversus viscerum mice. Nature 1997, 389, 963-966. [CrossRef] [PubMed]

14. Essner, J.J.; Amack, J.D.; Nyholm, M.K.; Harris, E.B.; Yost, H.J. Kupffer's vesicle is a ciliated organ of asymmetry in the zebrafish embryo that initiates left-right development of the brain, heart and gut. Development 2005, 132, 1247-1260. [CrossRef]

15. Kramer-Zucker, A.G.; Olale, F.; Haycraft, C.J.; Yoder, B.K.; Schier, A.F.; Drummond, I.A. Cilia-driven fluid flow in the zebrafish pronephros, brain and Kupffer's vesicle is required for normal organogenesis. Development 2005, 132, 1907-1921. [CrossRef]

16. Long, S.; Ahmad, N.; Rebagliati, M. The zebrafish nodal-related gene southpaw is required for visceral and diencephalic left-right asymmetry. Development 2003, 130, 2303-2316. [CrossRef]

17. Lowe, L.A.; Supp, D.M.; Sampath, K.; Yokoyama, T.; Wright, C.V.; Potter, S.S.; Overbeek, P.; Kuehn, M.R. Conserved left-right asymmetry of nodal expression and alterations in murine situs inversus. Nature 1996, 381, 158-161. [CrossRef]

18. Marques, S.; Borges, A.C.; Silva, A.C.; Freitas, S.; Cordenonsi, M.; Belo, J.A. The activity of the Nodal antagonist Cerl-2 in the mouse node is required for correct $\mathrm{L} / \mathrm{R}$ body axis. Genes Dev. 2004, 18, 2342-2347. [CrossRef]

19. Ryan, A.K.; Blumberg, B.; Rodriguez-Esteban, C.; Yonei-Tamura, S.; Tamura, K.; Tsukui, T.; de la Pena, J.; Sabbagh, W.; Greenwald, J.; Choe, S.; et al. Pitx2 determines left-right asymmetry of internal organs in vertebrates. Nature 1998, 394, 545-551. [CrossRef] 
20. Kitamura, K.; Miura, H.; Miyagawa-Tomita, S.; Yanazawa, M.; Katoh-Fukui, Y.; Suzuki, R.; Ohuchi, H.; Suehiro, A.; Motegi, Y.; Nakahara, Y.; et al. Mouse Pitx2 deficiency leads to anomalies of the ventral body wall, heart, extra- and periocular mesoderm and right pulmonary isomerism. Development 1999, 126, 5749-5758.

21. Campione, M.; Ros, M.A.; Icardo, J.M.; Piedra, E.; Christoffels, V.M.; Schweickert, A.; Blum, M.; Franco, D.; Moorman, A.F. Pitx2 expression defines a left cardiac lineage of cells: Evidence for atrial and ventricular molecular isomerism in the iv/iv mice. Dev. Biol. 2001, 231, 252-264. [CrossRef] [PubMed]

22. Lin, C.R.; Kioussi, C.; O'Connell, S.; Briata, P.; Szeto, D.; Liu, F.; Izpisua-Belmonte, J.C.; Rosenfeld, M.G. Pitx2 regulates lung asymmetry, cardiac positioning and pituitary and tooth morphogenesis. Nature 1999, 401, 279-282. [CrossRef] [PubMed]

23. Kirchhof, P.; Kahr, P.C.; Kaese, S.; Piccini, I.; Vokshi, I.; Scheld, H.H.; Rotering, H.; Fortmueller, L.; Laakmann, S.; Verheule, S.; et al. PITX2c is expressed in the adult left atrium, and reducing Pitx2c expression promotes atrial fibrillation inducibility and complex changes in gene expression. Circ. Cardiovasc. Genet. 2011, 4, 123-133. [CrossRef] [PubMed]

24. Ai, D.; Liu, W.; Ma, L.; Dong, F.; Lu, M.F.; Wang, D.; Verzi, M.P.; Cai, C.; Gage, P.J.; Evans, S.; et al. Pitx2 regulates cardiac left-right asymmetry by patterning second cardiac lineage-derived myocardium. Dev. Biol. 2006, 296, 437-449. [CrossRef]

25. Strungaru, M.H.; Dinu, I.; Walter, M.A. Genotype-phenotype correlations in Axenfeld-Rieger malformation and glaucoma patients with FOXC1 and PITX2 mutations. Investig. Ophthalmol. Vis. Sci. 2007, 48, 228-237. [CrossRef] [PubMed]

26. Reis, L.M.; Tyler, R.C.; Volkmann Kloss, B.A.; Schilter, K.F.; Levin, A.V.; Lowry, R.B.; Zwijnenburg, P.J.; Stroh, E.; Broeckel, U.; Murray, J.C.; et al. PITX2 and FOXC1 spectrum of mutations in ocular syndromes. Eur. J. Hum. Genet. 2012, 20, 1224-1233. [CrossRef]

27. Souzeau, E.; Siggs, O.M.; Zhou, T.; Galanopoulos, A.; Hodson, T.; Taranath, D.; Mills, R.A.; Landers, J.; Pater, J.; Smith, J.E.; et al. Glaucoma spectrum and age-related prevalence of individuals with FOXC1 and PITX2 variants. Eur. J. Hum. Genet. 2017, 25, 839-847. [CrossRef]

28. Semina, E.V.; Reiter, R.; Leysens, N.J.; Alward, W.L.M.; Small, K.W.; Datson, N.A.; Siegel-Bartelt, J.; BierkeNelson, D.; Bitoun, P.; Zabel, B.U.; et al. Cloning and characterization of a novel bicoid-related homeobox transcription factor gene, RIEG, involved in Rieger syndrome. Nat. Genet. 1996, 14, 392-399. [CrossRef]

29. Lenhart, K.F.; Lin, S.Y.; Titus, T.A.; Postlethwait, J.H.; Burdine, R.D. Two additional midline barriers function with midline lefty1 expression to maintain asymmetric Nodal signaling during left-right axis specification in zebrafish. Development 2011, 138, 4405-4410. [CrossRef]

30. Ishimaru, Y.; Yoshioka, H.; Tao, H.; Thisse, B.; Thisse, C.; Wright, C.V.; Hamada, H.; Ohuchi, H.; Noji, S. Asymmetric expression of antivin/lefty1 in the early chick embryo. Mech. Dev. 2000, 90, 115-118. [CrossRef]

31. Meno, C.; Shimono, A.; Saijoh, Y.; Yashiro, K.; Mochida, K.; Ohishi, S.; Noji, S.; Kondoh, H.; Hamada, H. lefty-1 is required for left-right determination as a regulator of lefty-2 and nodal. Cell 1998, 94, 287-297. [CrossRef]

32. Meno, C.; Gritsman, K.; Ohishi, S.; Ohfuji, Y.; Heckscher, E.; Mochida, K.; Shimono, A.; Kondoh, H.; Talbot, W.S.; Robertson, E.J.; et al. Mouse Lefty 2 and zebrafish antivin are feedback inhibitors of nodal signaling during vertebrate gastrulation. Mol. Cell 1999, 4, 287-298. [CrossRef]

33. Muller, P.; Rogers, K.W.; Jordan, B.M.; Lee, J.S.; Robson, D.; Ramanathan, S.; Schier, A.F. Differential Diffusivity of Nodal and Lefty Underlies a Reaction-Diffusion Patterning System. Science 2012, 336, 721-724. [CrossRef] [PubMed]

34. Meno, C.; Takeuchi, J.; Sakuma, R.; Koshiba-Takeuchi, K.; Ohishi, S.; Saijoh, Y.; Miyazaki, J.; ten Dijke, P.; Ogura, T.; Hamada, H. Diffusion of nodal signaling activity in the absence of the feedback inhibitor Lefty2. Dev. Cell 2001, 1, 127-138. [CrossRef]

35. Deng, X.; Zhou, J.; Li, F.F.; Yan, P.; Zhao, E.Y.; Hao, L.; Yu, K.J.; Liu, S.L. Characterization of nodal/TGF-lefty signaling pathway gene variants for possible roles in congenital heart diseases. PLoS ONE 2014, 9, e104535. [CrossRef]

36. Sivakumar, A.; Mahadevan, A.; Lauer, M.E.; Narvaez, R.J.; Ramesh, S.; Demler, C.M.; Souchet, N.R.; Hascall, V.C.; Midura, R.J.; Garantziotis, S.; et al. Midgut Laterality Is Driven by Hyaluronan on the Right. Dev. Cell 2018, 46, 533-551.e535. [CrossRef]

37. Ocana, O.H.; Coskun, H.; Minguillon, C.; Murawala, P.; Tanaka, E.M.; Galceran, J.; Munoz-Chapuli, R.; Nieto, M.A. A right-handed signalling pathway drives heart looping in vertebrates. Nature 2017, 549, 86. [CrossRef]

38. Mears, A.J.; Jordan, T.; Mirzayans, F.; Dubois, S.; Kume, T.; Parlee, M.; Ritch, R.; Koop, B.; Kuo, W.L.; Collins, C.; et al. Mutations of the forkhead/winged-helix gene, FKHL7, in patients with Axenfeld-Rieger anomaly. Am. J. Hum. Genet. 1998, 63, 1316-1328. [CrossRef]

39. Saadi, I.; Toro, R.; Kuburas, A.; Semina, E.; Murray, J.C.; Russo, A.F. An unusual class of PITX2 mutations in Axenfeld-Rieger syndrome. Birth Defects Res. A Clin. Mol. Teratol. 2006, 76, 175-181. [CrossRef]

40. Nishimura, D.Y.; Swiderski, R.E.; Alward, W.L.M.; Searby, C.C.; Patil, S.R.; Bennet, S.R.; Kanis, A.B.; Gastier, J.M.; Stone, E.M.; Sheffield, V.C. The forkhead transcription factor gene FKHL7 is responsible for glaucoma phenotypes which map to 6p25. Nat. Genet. 1998, 19, 140-147. [CrossRef]

41. Lehmann, O.J.; Ebenezer, N.D.; Jordan, T.; Fox, M.; Ocaka, L.; Payne, A.; Leroy, B.P.; Clark, B.J.; Hitchings, R.A.; Povey, S.; et al. Chromosomal duplication involving the forkhead transcription factor gene FOXC1 causes iris hypoplasia and glaucoma. Am. J. Hum. Genet. 2000, 67, 1129-1135. [CrossRef] [PubMed]

42. Nishimura, D.Y.; Searby, C.C.; Alward, W.L.; Walton, D.; Craig, J.E.; Mackey, D.A.; Kawase, K.; Kanis, A.B.; Patil, S.R.; Stone, E.M.; et al. A spectrum of FOXC1 mutations suggests gene dosage as a mechanism for developmental defects of the anterior chamber of the eye. Am. J. Hum. Genet. 2001, 68, 364-372. [CrossRef] [PubMed] 
43. Lines, M.A.; Kozlowski, K.; Kulak, S.C.; Allingham, R.R.; Heon, E.; Ritch, R.; Levin, A.V.; Shields, M.B.; Damji, K.F.; Newlin, A.; et al. Characterization and prevalence of PITX2 microdeletions and mutations in Axenfeld-Rieger malformations. Investig. Ophthalmol. Vis. Sci. 2004, 45, 828-833. [CrossRef]

44. Tumer, Z.; Bach-Holm, D. Axenfeld-Rieger syndrome and spectrum of PITX2 and FOXC1 mutations. Eur. J. Hum. Genet. 2009, 17, 1527-1539. [CrossRef]

45. Moog, U.; Bleeker-Wagemakers, E.M.; Crobach, P.; Vles, J.S.; Schrander-Stumpel, C.T. Sibs with Axenfeld-Rieger anomaly, hydrocephalus, and leptomeningeal calcifications: A new autosomal recessive syndrome? Am. J. Med. Genet. 1998, 78, 263-266. [CrossRef]

46. French, C.R.; Seshadri, S.; Destefano, A.L.; Fornage, M.; Arnold, C.R.; Gage, P.J.; Skarie, J.M.; Dobyns, W.B.; Millen, K.J.; Liu, T.; et al. Mutation of FOXC1 and PITX2 induces cerebral small-vessel disease. J. Clin. Investig. 2014, 124, 4877-4881. [CrossRef]

47. Aldinger, K.A.; Lehmann, O.J.; Hudgins, L.; Chizhikov, V.V.; Bassuk, A.G.; Ades, L.C.; Krantz, I.D.; Dobyns, W.B.; Millen, K.J. FOXC1 is required for normal cerebellar development and is a major contributor to chromosome 6p25.3 Dandy-Walker malformation. Nat. Genet. 2009, 41, 1037-1042. [CrossRef]

48. Calcagni, G.; Digilio, M.C.; Capolino, R.; Dallapiccola, B.; Marino, B. Concordant familial segregation of atrial septal defect and Axenfeld-Rieger anomaly in father and son. Clin. Dysmorphol. 2006, 15, 203-206. [CrossRef]

49. Gripp, K.W.; Hopkins, E.; Jenny, K.; Thacker, D.; Salvin, J. Cardiac anomalies in Axenfeld-Rieger syndrome due to a novel FOXC1 mutation. Am. J. Med. Genet. A 2013, 161A, 114-119. [CrossRef]

50. Grosso, S.; Farnetani, M.A.; Berardi, R.; Vivarelli, R.; Vanni, M.; Morgese, G.; Balestri, P. Familial Axenfeld-Rieger anomaly, cardiac malformations, and sensorineural hearing loss: A provisionally unique genetic syndrome? Am. J. Med. Genet. 2002, 111, 182-186. [CrossRef]

51. Gurbuz-Koz, O.; Atalay, T.; Koz, C.; Ilgin-Ruhi, H.; Yarangumeli, A.; Kural, G. Axenfeld-Rieger syndrome associated with truncus arteriosus: A case report. Turk. J. Pediatr. 2007, 49, 444-447. [PubMed]

52. Tonoki, H.; Harada, N.; Shimokawa, O.; Yosozumi, A.; Monzaki, K.; Satoh, K.; Kosaki, R.; Sato, A.; Matsumoto, N.; Iizuka, S. Axenfeld-Rieger anomaly and Axenfeld-Rieger syndrome: Clinical, molecular-cytogenetic, and DNA array analyses of three patients with chromosomal defects at 6p25. Am. J. Med. Genet. A 2011, 155A, 2925-2932. [CrossRef] [PubMed]

53. Chrystal, P.W.; Walter, M.A. Aniridia and Axenfeld-Rieger Syndrome: Clinical presentations, molecular genetics and current/emerging therapies. Exp Eye Res. 2019, 189, 107815. [CrossRef] [PubMed]

54. Kume, T.; Jiang, H.; Topczewska, J.M.; Hogan, B.L. The murine winged helix transcription factors, Foxc1 and Foxc2, are both required for cardiovascular development and somitogenesis. Genes Dev. 2001, 15, 2470-2482. [CrossRef]

55. Winnier, G.E.; Kume, T.; Deng, K.Y.; Rogers, R.; Bundy, J.; Raines, C.; Walter, M.A.; Hogan, B.L.M.; Conway, S.J. Roles for the winged helix transcription factors MF1 and MFH1 in cardiovascular development revealed by nonallelic noncomplementation of null alleles. Dev. Biol. 1999, 213, 418-431. [CrossRef]

56. Seo, S.; Kume, T. Forkhead transcription factors, Foxc1 and Foxc2, are required for the morphogenesis of the cardiac outflow tract. Dev. Biol. 2006, 296, 421-436. [CrossRef]

57. Dutton, J.R.; Antonellis, A.; Carney, T.J.; Rodrigues, F.S.; Pavan, W.J.; Ward, A.; Kelsh, R.N. An evolutionarily conserved intronic region controls the spatiotemporal expression of the transcription factor Sox10. BMC Dev. Biol. 2008, 8, 105. [CrossRef]

58. Nüsslein-Volhard, C.; Dahm, R. Zebrafish: A Practical Approach, 1st ed.; Oxford University Press: Oxford, UK; New York, NY, USA, 2002.

59. Kimmel, C.B.; Ballard, W.W.; Kimmel, S.R.; Ullmann, B.; Schilling, T.F. Stages of embryonic development of the zebrafish. Dev. Dyn. 1995, 203, 253-310. [CrossRef]

60. Xu, P.; Balczerski, B.; Ciozda, A.; Louie, K.; Oralova, V.; Huysseune, A.; Crump, J.G. Fox proteins are modular competency factors for facial cartilage and tooth specification. Development 2018, 145. [CrossRef]

61. Wang, G.; Yost, H.J.; Amack, J.D. Analysis of gene function and visualization of cilia-generated fluid flow in Kupffer's vesicle. J. Vis. Exp. 2013. [CrossRef]

62. Gongal, P.A.; Waskiewicz, A.J. Zebrafish model of holoprosencephaly demonstrates a key role for TGIF in regulating retinoic acid metabolism. Hum. Mol Genet. 2008, 17, 525-538. [CrossRef] [PubMed]

63. Yelon, D.; Ticho, B.; Halpern, M.E.; Ruvinsky, I.; Ho, R.K.; Silver, L.M.; Stainier, D.Y.R. The bHLH transcription factor Hand2 plays parallel roles in zebrafish heart and pectoral fin development. Development 2000, 127, 2573-2582. [PubMed]

64. Odenthal, J.; Nusslein-Volhard, C. fork head domain genes in zebrafish. Dev. Genes Evol. 1998, 208, 245-258. [CrossRef]

65. Ji, Y.; Buel, S.M.; Amack, J.D. Mutations in zebrafish pitx2 model congenital malformations in Axenfeld-Rieger syndrome but do not disrupt left-right placement of visceral organs. Dev. Biol. 2016, 416, 69-81. [CrossRef] [PubMed]

66. Skarie, J.M.; Link, B.A. FoxC1 is essential for vascular basement membrane integrity and hyaloid vessel morphogenesis. Investig. Ophthalmol. Vis. Sci. 2009, 50, 5026-5034. [CrossRef]

67. Westerfield, M. The Zebrafish Book. A Guide for the Laboratory Use of Zebrafish (Danio Rerio), 4th ed.; University of Oregon Press: Eugene, OR, USA, 2000.

68. Lowery, L.A.; Sive, H. Initial formation of zebrafish brain ventricles occurs independently of circulation and requires the nagie oko and snakehead/atp1a1a.1 gene products. Development 2005, 132, 2057-2067. [CrossRef]

69. Meeker, N.D.; Hutchinson, S.A.; Ho, L.; Trede, N.S. Method for isolation of PCR-ready genomic DNA from zebrafish tissues. Biotechniques 2007, 43, 610-614. [CrossRef] 
70. Brody, J.R.; Kern, S.E. Sodium boric acid: A Tris-free, cooler conductive medium for DNA electrophoresis. Biotechniques 2004, 36, 214-216. [CrossRef]

71. Topczewska, J.M.; Topczewski, J.; Solnica-Krezel, L.; Hogan, B.L. Sequence and expression of zebrafish foxc1a and foxc1b, encoding conserved forkhead/winged helix transcription factors. Mech. Dev. 2001, 100, 343-347. [CrossRef]

72. Nagy, E.; Maquat, L.E. A rule for termination-codon position within intron-containing genes: When nonsense affects RNA abundance. Trends Biochem. Sci. 1998, 23, 198-199. [CrossRef]

73. Thermann, R.; Neu-Yilik, G.; Deters, A.; Frede, U.; Wehr, K.; Hagemeier, C.; Hentze, M.W.; Kulozik, A.E. Binary specification of nonsense codons by splicing and cytoplasmic translation. EMBO J. 1998, 17, 3484-3494. [CrossRef]

74. Cusack, B.P.; Arndt, P.F.; Duret, L.; Roest Crollius, H. Preventing Dangerous Nonsense: Selection for Robustness to Transcriptional Error in Human Genes. PLoS Genet. 2011, 7, e1002276. [CrossRef]

75. Berry, F.B.; Saleem, R.A.; Walter, M.A. FOXC1 transcriptional regulation is mediated by N- and C-terminal activation domains and contains a phosphorylated transcriptional inhibitory domain. J. Biol. Chem. 2002, 277, 10292-10297. [CrossRef] [PubMed]

76. Ferre-Fernández, J.J.; Sorokina, E.A.; Thompson, S.; Collery, R.F.; Nordquist, E.; Lincoln, J.; Semina, E.V. Disruption of foxc1 genes in zebrafish results in dosage-dependent phenotypes overlapping Axenfeld-Rieger syndrome. Hum. Mol. Genet. 2020, 29, 2723-2735. [CrossRef] [PubMed]

77. Umali, J.; Hawkey-Noble, A.; French, C.R. Loss of foxc1 in zebrafish reduces optic nerve size and cell number in the retinal ganglion cell layer. Vis. Res. 2019, 156, 66-72. [CrossRef] [PubMed]

78. Lehmann, O.J.; Ebenezer, N.D.; Ekong, R.; Ocaka, L.; Mungall, A.J.; Fraser, S.; McGill, J.I.; Hitchings, R.A.; Khaw, P.T.; Sowden, J.C.; et al. Ocular developmental abnormalities and glaucoma associated with interstitial $6 \mathrm{p} 25$ duplications and deletions. Investig. Ophthalmol. Vis. Sci. 2002, 43, 1843-1849.

79. Bisgrove, B.W.; Essner, J.J.; Yost, H.J. Multiple pathways in the midline regulate concordant brain, heart and gut left-right asymmetry. Development 2000, 127, 3567-3579.

80. Welsh, I.C.; Kwak, H.; Chen, F.L.; Werner, M.; Shopland, L.S.; Danko, C.G.; Lis, J.T.; Zhang, M.; Martin, J.F.; Kurpios, N.A. Chromatin Architecture of the Pitx2 Locus Requires CTCF- and Pitx2-Dependent Asymmetry that Mirrors Embryonic Gut Laterality. Cell Rep. 2015, 13, 337-349. [CrossRef]

81. Nonaka, S.; Shiratori, H.; Saijoh, Y.; Hamada, H. Determination of left-right patterning of the mouse embryo by artificial nodal flow. Nature 2002, 418, 96-99. [CrossRef]

82. Stubbs, J.L.; Oishi, I.; Belmonte, J.C.I.; Kintner, C. The forkhead protein Foxj1 specifies node-like cilia in Xenopus and zebrafish embryos. Nat. Genet. 2008, 40, 1454-1460. [CrossRef]

83. Yu, X.; Ng, C.P.; Habacher, H.; Roy, S. Foxj1 transcription factors are master regulators of the motile ciliogenic program. Nat. Genet. 2008, 40, 1445-1453. [CrossRef] [PubMed]

84. Campbell, E.P.; Quigley, I.K.; Kintner, C. Foxn4 promotes gene expression required for the formation of multiple motile cilia. Development 2016, 143, 4654-4664, Correction: Development 2017, 144, 731-731. [CrossRef]

85. Seo, S.; Chen, L.; Liu, W.; Zhao, D.; Schultz, K.M.; Sasman, A.; Liu, T.; Zhang, H.F.; Gage, P.J.; Kume, T. Foxc1 and Foxc2 in the Neural Crest Are Required for Ocular Anterior Segment Development. Investig. Ophthalmol. Vis. Sci. 2017, 58, 1368-1377. [CrossRef]

86. Li, J.; Yue, Y.; Dong, X.; Jia, W.; Li, K.; Liang, D.; Dong, Z.; Wang, X.; Nan, X.; Zhang, Q.; et al. Zebrafish foxc1a plays a crucial role in early somitogenesis by restricting the expression of aldh1a2 directly. J. Biol. Chem. 2015, 290, 10216-10228. [CrossRef] [PubMed]

87. Carmona, S.; Freitas, M.D.; Froufe, H.; Simoes, M.J.; Sampaio, M.J.; Silva, E.D.; Egas, C. Novel de novo FOXC1 nonsense mutation in an Axenfeld-Rieger syndrome patient. Am. J. Med. Genet. A 2017, 173, 1607-1610. [CrossRef] [PubMed]

88. Blatt, E.N.; Yan, X.H.; Wuerffel, M.K.; Hamilos, D.L.; Brody, S.L. Forkhead transcription factor HFH-4 expression is temporally related to ciliogenesis. Am. J. Respir. Cell Mol. Biol. 1999, 21, 168-176. [CrossRef] [PubMed]

89. Ang, S.L.; Rossant, J. HNF-3 $\beta$ is essential for node and notochord formation in mouse development. Cell 1994, 78, 561-574. [CrossRef]

90. Pogoda, H.M.; Solnica-Krezel, L.; Driever, W.; Meyer, D. The zebrafish forkhead transcription factor FoxH1/Fast1 is a modulator of nodal signaling required for organizer formation. Curr. Biol. 2000, 10, 1041-1049. [CrossRef]

91. Berry, F.B.; Lines, M.A.; Oas, J.M.; Footz, T.; Underhill, D.A.; Gage, P.J.; Walter, M.A. Functional interactions between FOXC1 and PITX2 underlie the sensitivity to FOXC1 gene dose in Axenfeld-Rieger syndrome and anterior segment dysgenesis. Hum. Mol. Genet. 2006, 15, 905-919. [CrossRef] 